\title{
An Unusual Polarographic Behavior of Selenite in the Presence of Some Cations
}

\author{
Recai İNAM and Güler SoMER ${ }^{\dagger}$ \\ Gazi Üniversitesi, Fen-Edebiyat Fakültesi, Kimya Bölümü, 06500 Ankara, Turkey
}

\begin{abstract}
During a differential pulse polarographic determination of selenium, the selenite peak was diminished upon the addition of some ions, such as lead, copper and cadmium. On the other hand, the addition of selenite ion had the same effect on the peaks of the mentioned ions. In both cases a new reduction peak appeared at a more positive potential with respect to the selenite and present ion reductions. This observation is attributed to an intermetallic compound formation between selenium and the ions present. The peak is brought about by a reduction of the lead ion, which afterwards forms an intermetallic compound with selenium adsorbed on the mercury-drop surface $\left(\mathrm{Pb}^{2+}+\mathrm{Se}_{(\mathrm{ads})}+2 \mathrm{e} \rightleftarrows \mathrm{PbSe}_{(\mathrm{ads})}\right)$. Temperaturedependence studies also revealed that the observed phenomenon is a surface reaction.
\end{abstract}

Keywords Differential pulse polarography, interference problem, selenium, lead, cadmium, copper, intermetallic compound

Selenium is an essential trace element in the human body. A lack or excess of selenium leads to several disease. A sensitive method of determining selenium is therefore necessary for studying diseases involving a lack selenium or selenium poisoning. The determination of nanogram levels of selenium in biological material is usually difficult. Analysis by atomic absorption spectroscopy has been shown to be a quick and simple method using the hydride vapor generation technique. ${ }^{1,2}$ Although there are several references to this method, there are also a number of factors generally overlooked, such as interferences and losses through volatilization at high temperatures. The detection limit is also low compared to that of voltammetric methods.

Modern voltammetric methods have been used for determining trace amounts of selenium. Of these, anodic stripping voltammetry $(\mathrm{ASV})^{3-5}$, cathodic stripping voltammetry $(\mathrm{CSV})^{6-8}$, adsorptive stripping voltammetry (Ads. SV) ${ }^{9,10}$ and differential pulse polarography (DPP) ${ }^{11,12}$ are the most popular. In our previous studies ${ }^{3,13}$ we observed a phenomenon during the anodic stripping voltammetric determination of selenite in the presence of copper. When selenite was added to a solution containing copper (in order to determine selenium, standard additions were made) the peak height decreased and a new peak appeared at a more negative potential than that for selenium oxidation. This new peak was attributed to an intermetallic compound between selenium and copper. This fact was thoroughly investigated using cyclic voltammetry ${ }^{13}$ and it was shown that there was intermetallic compound formation on the hanging mercury-drop electrode, and

\footnotetext{
$\doteqdot$ To whom correspondence should be addressed.
}

that the new peak during stripping was due to a reduction of this compound. A similar behavior was stated ${ }^{6-8}$ to happen between copper and selenium during the cathodic and anodic stripping voltammetric determination of selenium.

During our DPP studies we observed that selenite and some ions, such as copper, lead and cadmium, diminished the peak of each other. This unusual behavior may not be due to the formation of metal selenites, since it was also observed in $2 \mathrm{M}$ acid solutions, where selenite formation was not possible. Because of this phenomenon, most of the electroanalytical determinations in solutions which contain both selenite and at least one of these ions would be wrong. It was thus found that it is important to investigate this behavior thoroughly. The aim of this study was to determine the kind of interaction taking place between selenite and the mentioned ions.

\section{Experimental}

\section{Apparatus}

A PAR Model 174A polarographic analyzer system, equipped with a PAR mercury-drop timer, was used. The drop time of the mercury electrode was approximately $2-3 \mathrm{~s}\left(2.75 \mathrm{mg} \mathrm{s}^{-1}\right)$. A saturated calomel electrode (SCE) was used as the reference, and a platinum wire as the counter electrode. The polarograms were recorded with a Linseis LY $1600 \mathrm{X}-\mathrm{Y}$ recorder (Linseis, Selb, Germany). The $\mathrm{pH}$ values were measured with a Hanna HI 8521 pH meter. Differential pulse polarograms were recorded under the conditions of a drop life of $1 \mathrm{~s}$, a scan rate of $5 \mathrm{mV} \mathrm{s}^{-1}$ and a pulse 
amplitude of $50 \mathrm{mV}$.

\section{Reagents}

All of the reagents used were of analytical-reagent grade. Triply distilled water was used throughout. The mercury (proanalysi) used in the dropping-mercury electrode was obtained from Merck (Darmstadt, Germany). Contaminated mercury was cleaned by passing it successively through dilute $\mathrm{HNO}_{3}$ and water columns in the form of fine droplets. The collected mercury was dried between sheets of filter-paper. Before use, a polarogram of this mercury was recorded in order to confirm the absence of impurities.

A $0.1 \mathrm{~mol} \mathrm{dm}^{-3}$ stock standard selenite solution was prepared by dissolving $1.1977 \mathrm{~g}$ of $\mathrm{SeO}_{2}$ in $100 \mathrm{~cm}^{3}$ of hot water. Solutions of $1 \times 10^{-3}, 1 \times 10^{-4}$ and $1 \times 10^{-5} \mathrm{~mol}$ $\mathrm{dm}^{-3}$ were prepared before every use in order to avoid the aging process of solution. Dilute solutions were prepared before every use. Britton-Robinson buffer solutions (B-R solution) were used for $\mathrm{pH}=2.3$ and 4.3.

\section{Procedure}

The solution was deaerated for 10 min with pure nitrogen $(99.999 \%)$. Then, differential pulse polarograms were recorded under the conditions of a drop life of $1 \mathrm{~s}$, a scan rate of $5 \mathrm{mV} \mathrm{s}^{-1}$ and a pulse amplitude of $50 \mathrm{mV}$.

\section{Results and Discussion}

During the polarographic determination of selenite, when selenite solutions were added to solutions of some ions, such as lead, cadmium and copper, it was observed that the peak height of the mentioned ions were decreasing. To investigate this behavior, solutions of various compositions were prepared and their DPP peaks were observed under different conditions.

\section{Effect of lead ion additions on the selenite peak}

Three peaks were observed for selenite ion in a $0.1 \mathrm{M}$ $\mathrm{HCl}$ solution. ${ }^{14}$ The peak at $-0.54 \mathrm{~V}$ responded well to selenite ion additions. However, when lead solution was added to this solution, different results were obtained, depending on the lead-to-selenium concentration ratio. The results can be summarized as follows:

i) When a $300 \mu \mathrm{l}$ portion of $1 \times 10^{-3} \mathrm{M}$ selenite solution was added to $10 \mathrm{ml} 0.1 \mathrm{M} \mathrm{HCl}$ solution and a polarogram was taken, a reduction peak at $-0.54 \mathrm{~V}$, which belongs to selenite, was observed. When a lead-ion solution was added to this solution the peak at -0.54 $\mathrm{V}$ decreased and a new peak at $-0.33 \mathrm{~V}$ appeared, as can be observed in Fig. 1. This peak at $-0.33 \mathrm{~V}$ was observed only when selenite and lead were present together, which suggests an interaction between these ions.

ii) The peak at $-0.33 \mathrm{~V}$ increased upon the continuous additions of lead ion until a one-to-one mole ratio for selenite and lead ion was approached (Fig. 1). iii) The peak for selenium at $-0.54 \mathrm{~V}$ decreased upon lead-ion additions, as can be seen in Fig. 1; for $1 \mathrm{~mol}$ of lead nearly $1 \mathrm{~mol}$ of selenite was used up.

iv) During lead-ion additions to a selenite solution, when the lead concentration exceeded the selenite concentration, another peak at $-0.41 \mathrm{~V}$ appeared, as can be seen in Fig. 2. According to our preliminary studies, this peak must belong to lead. Since selenite ion was used up by lead ion to form a compound which gives a peak at $-0.33 \mathrm{~V}$, the free lead ion could be observed at $-0.41 \mathrm{~V}$. As expected, this peak increased upon the addition of lead ion.

v) When more selenite was added to a solution containing selenite and excess lead, the peak for lead at $-0.41 \mathrm{~V}$ decreased and the peak at $-0.33 \mathrm{~V}$ increased, as shown in Fig. 3.

vi) When the peak for lead was lost with continuous additions of selenite, the peak for selenium at -0.54 $\mathrm{V}$ started to increase as can be seen in Fig. 3. The peak at $-0.33 \mathrm{~V}$, however, became constant when one of these ions was used up.

vii) The same behavior was also observed with solutions containing $10^{-6}$ and $10^{-7} \mathrm{M}$ selenite and the mentioned ions.

\section{Effect of selenite additions on lead peak}

For the lead ion a peak at $-0.41 \mathrm{~V}$ was observed, which responded well upon lead-ion additions. When a small amount of selenite was added to this solution a new peak at $-0.33 \mathrm{~V}$ appeared, and the peak for lead at $-0.41 \mathrm{~V}$ decreased, as can be observed in Fig. 4. When

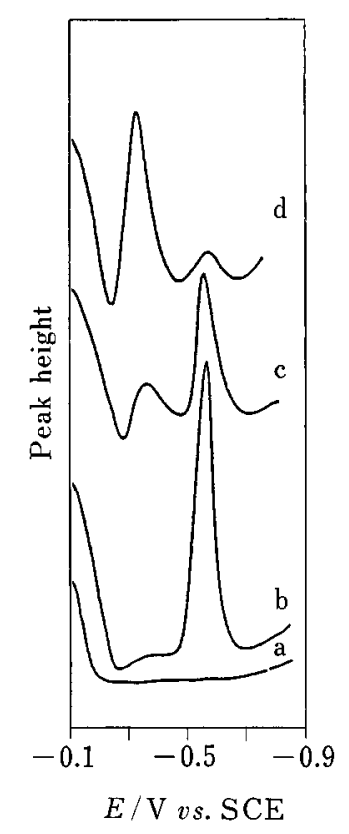

Fig. 1 Effect of lead-ion additions on the selenite peak. (a), 10 ml $0.1 \mathrm{M} \mathrm{HCl}$; (b), (a)+300 $\mu \mathrm{l} 1 \times 10^{-3} \mathrm{M} \mathrm{Se}(\mathrm{IV}) ;(\mathrm{c}),(\mathrm{b})+100$ $\mu \mathrm{l} 1 \times 10^{-3} \mathrm{M} \mathrm{Pb}(\mathrm{II})$; (d), (c)+200 $\mu \mathrm{l} 1 \times 10^{-3} \mathrm{M} \mathrm{Pb}(\mathrm{II})$. Drop life $1 \mathrm{~s}$, scan rate $5 \mathrm{mV} \mathrm{s}^{-1}$ and pulse amplitude $50 \mathrm{mV}$. 


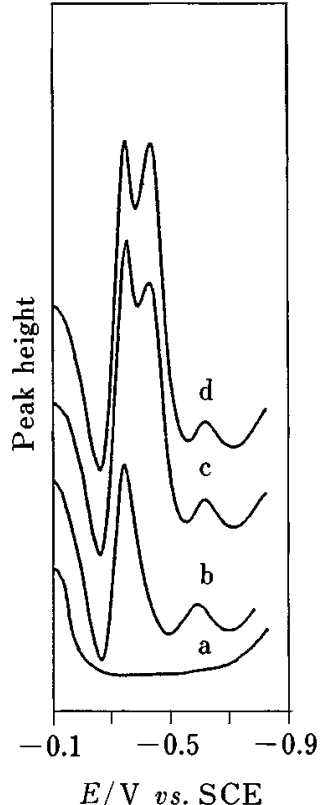

Fig. 2 Addition of lead ion when the lead concentration was equal to the selenite concentration. (a), $10 \mathrm{ml} 0.1 \mathrm{M} \mathrm{HCl}$; (b), (a)+300 $\mu \mathrm{l} 1 \times 10^{-3} \mathrm{M} \mathrm{Se}(\mathrm{IV})$ and $300 \mu \mathrm{l} 1 \times 10^{-3} \mathrm{M} \mathrm{Pb}(\mathrm{II})$; (c), (b)+300 $\mu \mathrm{l} 1 \times 10^{-3} \mathrm{M} \mathrm{Pb}(\mathrm{II})$; (d), (c) $+100 \mu \mathrm{l} 1 \times 10^{-3} \mathrm{M}$ $\mathrm{Pb}$ (II). Drop life $1 \mathrm{~s}$, scan rate $5 \mathrm{mV} \mathrm{s}^{-1}$ and pulse amplitude $50 \mathrm{mV}$.

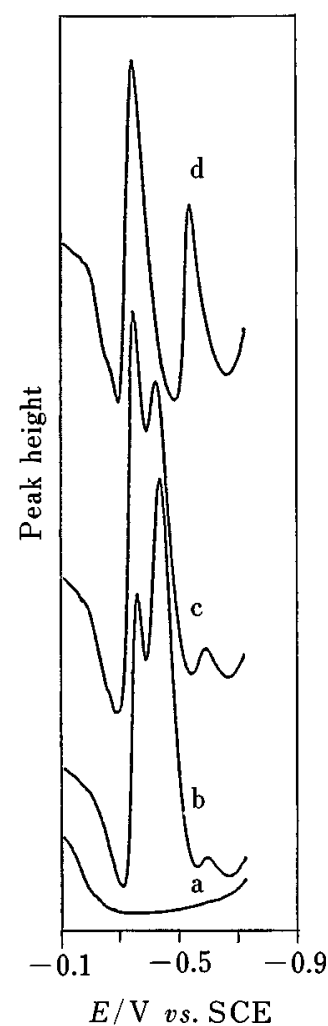

Fig. 3 Addition of selenite ion when the lead concentration exceeded the selenite concentration. (a), $10 \mathrm{ml} 0.1 \mathrm{M} \mathrm{HCl}$; (b), (a)+300 $\mu 11 \times 10^{-3} \mathrm{M} \mathrm{Se}(\mathrm{IV})$ and $1000 \mu \mathrm{l} 1 \times 10^{-3} \mathrm{M}$ $\mathrm{Pb}(\mathrm{II}) ;(\mathrm{c}),(\mathrm{b})+200 \mu \mathrm{l} 1 \times 10^{-3} \mathrm{M} \mathrm{Se}(\mathrm{IV}) ;(\mathrm{d}),(\mathrm{c})+900 \mu \mathrm{l}$ $1 \times 10^{-3} \mathrm{M} \mathrm{Se}(\mathrm{IV})$. Drop life $1 \mathrm{~s}$, scan rate $5 \mathrm{mV} \mathrm{s}^{-1}$ and pulse amplitude $50 \mathrm{mV}$. the lead peak disappeared with continuous addition of selenite ion, a new peak at $-0.54 \mathrm{~V}$ belonging to the selenite ion appeared. This peak increased continuously with selenite additions. Thus, the same results were obtained, although the initial solutions were different.

\section{Effect of cadmium and copper}

Similar results were observed for solutions containing copper, cadmium and selenite. While cadmium had a peak at $-0.62 \mathrm{~V}$, the addition of selenite at the same concentration decreased this peak, and a new peak at $-0.41 \mathrm{~V}$ appeared. In the case of copper, however, in contrast to ASV and CSV studies, the interference was not as strong as that for lead and cadmium. When the copper concentration was more than ten-times that of selenite a small interference was observed.

\section{Effect of temperature}

A polarogram of a solution containing $400 \mu \mathrm{l} 1 \times 10^{-3}$ $\mathrm{M} \mathrm{Pb}^{2+}$ and $100 \mu \mathrm{l} 1 \times 10^{-3} \mathrm{M} \mathrm{Se}(\mathrm{IV})$ was first taken at $25^{\circ} \mathrm{C}$. A peak at $-0.33 \mathrm{~V}$ belonging to lead-selenium compound and a peak at $-0.41 \mathrm{~V}$ for lead was obtained. This solution was warmed up to $45^{\circ} \mathrm{C}$, and a polarogram was taken once more. The peak at $-0.33 \mathrm{~V}$ disap-

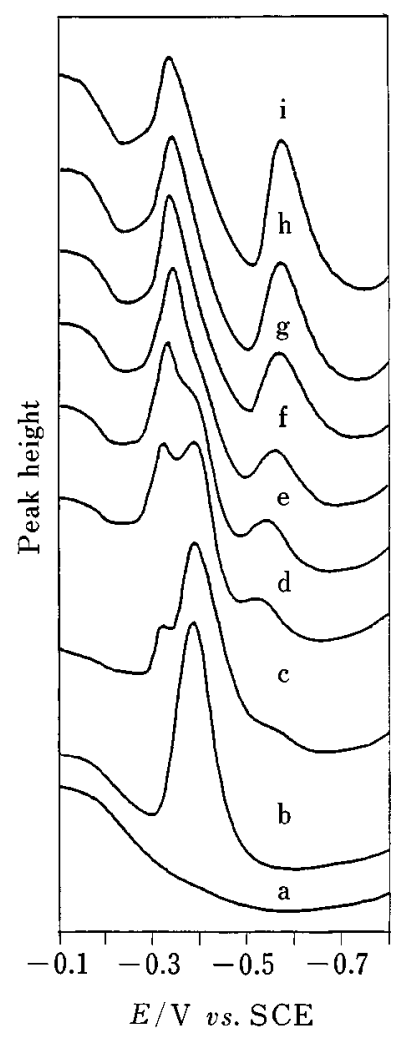

Fig. 4 Effect of selenite-ion additions on the lead peak. (a), 10

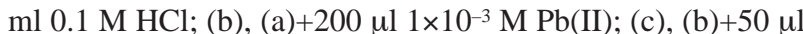
$1 \times 10^{-3} \mathrm{M} \mathrm{Se}(\mathrm{IV}) ;(\mathrm{d}),(\mathrm{c})+50 \mu \mathrm{l} 1 \times 10^{-3} \mathrm{M} \mathrm{Se}(\mathrm{IV}) ;(\mathrm{e}),(\mathrm{d})+50$ $\mu 11 \times 10^{-3} \mathrm{M} \mathrm{Se}(\mathrm{IV})$; (f), (e) $+50 \mu 11 \times 10^{-3} \mathrm{M} \mathrm{Se}(\mathrm{IV}) ;(\mathrm{g})$, (f) $+50 \mu \mathrm{l} 1 \times 10^{-3} \mathrm{M} \mathrm{Se}(\mathrm{IV})$; (h), (g) $+50 \mu \mathrm{l} 1 \times 10^{-3} \mathrm{M} \mathrm{Se}(\mathrm{IV})$; (i), (h) $+50 \mu \mathrm{l} 1 \times 10^{-3} \mathrm{M}$ Se(IV). Drop life $1 \mathrm{~s}$, scan rate $5 \mathrm{mV}$ $\mathrm{s}^{-1}$ and pulse amplitude $50 \mathrm{mV}$. 
peared, and the lead peak increased, as can be seen in Fig. 5. This fact was expected, since the adsorption decreased at higher temperatures and intermetallic compound formation could not take place at the drop surface. After the solution had cooled down to $25^{\circ} \mathrm{C}$ once more, a polarogram was taken. The same two peaks at $-0.33 \mathrm{~V}$ and $-0.41 \mathrm{~V}$ were observable again. The disappearance of the peak at $-0.33 \mathrm{~V}$ may be an indication of the formation of this compound on the drop surface where one of the elements was adsorbed.

\section{Effect of $p H$}

The same phenomenon was observed for 2, 1 and 0.1 $\mathrm{M} \mathrm{HCl}$ solutions and also in $\mathrm{pH}=2.3 \mathrm{~B}-\mathrm{R}$ buffer solutions. However, in a $\mathrm{pH}=4.3 \mathrm{~B}-\mathrm{R}$ buffer solution, the lead peak was not observed, and the addition of this ion did not diminish the selenium peak. This can be explained by complex formation between lead and acetate in the buffer. The complexed lead could not react with selenium. The effect of the $\mathrm{pH}$ on the lead

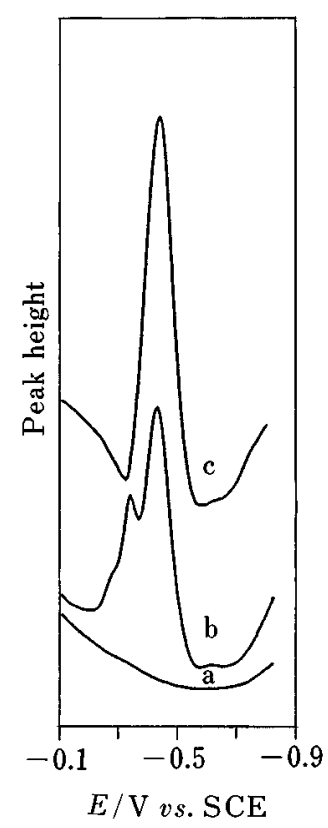

Fig. 5 Effect of the temperature on the lead-selenium compound. (a), $10 \mathrm{ml} 0.1 \mathrm{M} \mathrm{HCl}$; (b), $400 \mu \mathrm{l} 1 \times 10^{-3} \mathrm{M} \mathrm{Pb}(\mathrm{II})$ and $100 \mu \mathrm{l} 1 \times 10^{-3} \mathrm{M} \mathrm{Se}(\mathrm{IV})$ at $25^{\circ} \mathrm{C}$; (c), (b) at $45^{\circ} \mathrm{C}$. Drop life $1 \mathrm{~s}$, scan rate $5 \mathrm{mV} \mathrm{s}^{-1}$ and pulse amplitude $50 \mathrm{mV}$.

Table 1 Effect of $\mathrm{pH}$ on peak potentials (V) of $\mathrm{Se}, \mathrm{Pb}, \mathrm{PbSe}$, $\mathrm{Cd}$ and $\mathrm{CdSe}$

\begin{tabular}{lccccc}
\hline \multicolumn{1}{c}{$\mathrm{pH}$} & $\mathrm{Se}$ & $\mathrm{Pb}$ & $\mathrm{PbSe}$ & $\mathrm{Cd}$ & $\mathrm{CdSe}$ \\
\hline $4.3^{\mathrm{a}}$ & -0.71 & - & - & -0.59 & -0.38 \\
$2.3^{\mathrm{a}}$ & -0.58 & -0.35 & -0.29 & -0.60 & -0.40 \\
$0.1 \mathrm{M} \mathrm{HCl}$ & -0.54 & -0.41 & -0.33 & -0.62 & -0.41 \\
$1 \mathrm{M} \mathrm{HCl}$ & -0.51 & -0.47 & -0.41 & -0.66 & -0.46 \\
$2 \mathrm{M} \mathrm{HCl}$ & -0.48 & -0.50 & -0.43 & -0.69 & -0.48 \\
\hline
\end{tabular}

a. Britton-Robinson buffer solution. and cadmium peak potentials is summarized in Table 1 . The peak which was obtained in the presence of selenium and lead, and the peak obtained in the presence of selenium and cadmium, are represented by $\mathrm{PbSe}$ and CdSe, respectively.

As can be observed in Table 1, the peak potential for selenium shifts to more negative potentials with increasing $\mathrm{pH}$, as expected. On the other hand, lead and cadmium reduction peaks and $\mathrm{PbSe}$ and $\mathrm{CdSe}$ formation peaks are shifted to more positive potentials with $\mathrm{pH}$.

\section{The mechanism}

We have to explain why the selenium peak and the peaks of the above-mentioned ions decrease upon the addition of one of these ions, and the new peak which is formed when both of these ions are present.

It is known that under polarographic conditions selenite develops three peaks in an acidic medium. ${ }^{14,15}$ First, it is reduced to elemental selenium at between 0 and $-0.2 \mathrm{~V}$ (Eq.(1)), then to $\mathrm{H}_{2} \mathrm{Se}$ at around $-0.5 \mathrm{~V}$, and finally to $\mathrm{HgSe}$. When lead and selenium are present together, there is clearly a reaction between the reduced selenium (at about $-0.2 \mathrm{~V}$ ) and the lead ion, which decreases their peaks. As summarized in Table 1, the new product is more easily reduced than both of the elements. Combining these results lead us to the following mechanism:

$$
6 \mathrm{H}^{+}+\mathrm{SeO}_{3}{ }^{2-}+4 \mathrm{e}^{-} \rightleftarrows \mathrm{Se}_{(\mathrm{ads})}+3 \mathrm{H}_{2} \mathrm{O}
$$

and

$$
\mathrm{Se}_{(\mathrm{ads})}+\mathrm{Pb}^{2+}+2 \mathrm{e}^{-} \rightleftarrows \mathrm{PbSe}_{(\mathrm{ads})}
$$

The peak at $-0.33 \mathrm{~V}$ is attributed to the formation of an intermetallic compound, which is formed from elemental selenium adsorbed on the electrode surface. This reduction takes place at more positive potentials than do selenite and lead reduction, because of intermetallic compound formation. It was observed that the reduction potential of lead shifted to more positive potentials with the $\mathrm{pH}$. This fact is also an indication that the peak at $-0.33 \mathrm{~V}$ is due to the formation of the $\mathrm{PbSe}$ compound via the reduction of lead ion, and not the selenite ion, since the reduction potential of selenite shifted to more positive values at a lower $\mathrm{pH}$.

According to temperature-dependence investigations on the PbSe formation peak, we found that this peak decreased with temperature. Since the adsorption decreases with temperature, this fact also emphasizes that the observed phenomenon is a surface reaction. An intermetallic compound formation between copper and selenium during $\mathrm{ASV}^{3}$ and $\mathrm{CSV}^{6,8}$ determinations has been mentioned before. It seems that in DPP measurements when lead and selenium are present together, the same kind of intermetallic compound formation takes place. However, in ASV studies the new peak was found to be brought about by a reduction of the 
intermetallic compound; in DPP studies it was brought about in different way, as given in the mechanism. Because of this interference, care must be taken in the polarographic determination of the mentioned elements. However, in our recent studies we made use of the $\mathrm{PbSe}$ peak for determining selenium in biological materials. ${ }^{16}$

\section{References}

1. K. C. Thompson and D. R. Thomerson, Analyst [London], 99, 595 (1974).

2. R. J. Mailer and J. E. Paretley, Analyst [London], 108, 1060 (1983).

3. H. Aydın and G. Somer, Anal. Sci., 5, 89 (1989).

4. R. S. Posey and R. W. Andrews, Anal. Chim. Acta, 124, 107 (1981)

5. H. Aydın and A. H. Yahaya, Analyst [London], 117, 43 (1992).
6. S. B. Adeloju, A. M. Bond and H. C. Hughes, Anal. Chim. Acta, 148, 59 (1983).

7. W. Holak and J. J. Specchio, Analyst [Londan], 119, 2179 (1994).

8. S. B. Adeloju, A. M. Bond, M. H. Briggs and H. C. Hughes, Anal. Chem., 55, 2076 (1983).

9. J. Wang and C. Sun, J. Electroanal. Chem., 291, 59 (1990).

10. S. Tanaka, K. Sugawara and M. Taga, Anal. Sci., 6, 475 (1990).

11. G. E. Batley, Anal. Chim. Acta, 187, 109 (1986).

12. S. B. Adeloju, A. M. Bond and M. S. Briggs, Anal. Chem., 57, 1386 (1985).

13. G. Somer and M. S. Karacan, Electroanalysis, 6, 527 (1994).

14. E. Hasdemir and G. Somer, unpublished results.

15. L. Schwaer and K. Suchy, Collect. Czec. Chem. Commun., 7, 25 (1935)

16. R. İnam and G. Somer, Talanta, in press (1998).

(Received November 22, 1996) (Accepted October 20, 1997) 